\title{
Diagnosis of pathologies in ancient (seventeenth-eighteenth centuries) decorative blue-and-white ceramic tiles: Green stains in the glazes of a panel depicting Lisbon prior to the 1755 earthquake
}

\author{
Teresa P. Silva ${ }^{1}$, Maria-Ondina Figueiredo, ${ }^{1,2}$, Maria-Alexandra Barreiros ${ }^{3}$, \\ Maria-Isabel Prudêncio4
}

${ }^{1}$ LNEG-National Laboratory for Energy and Geology, Unity of Mineral Resources and Geophysics, Amadora, Portugal, ${ }^{2}$ CENIMAT/I3N, Materials Science Department, Faculty of Science and Technology, New University, Lisbon, Portugal, ${ }^{3}$ LNEG, Unity of Product Engineering, Lisboa, Portugal, ${ }^{4}$ IST/ITN, Universidade Técnica de Lisboa, Sacavém, Portugal

Decorative panels of ceramic glazed tiles comprise a valuable cultural heritage in Mediterranean countries. Their preservation requires the development of a systematic scientific approach. Exposure to an open-air environment allows for a large span of deterioration effects. Successfully overcoming these effects demands a careful identification of involved degradation processes. Among these, the development of micro-organisms and concomitant glaze surface staining is a very common effect observed in panels manufactured centuries ago. This paper describes a study on the nature of green stains appearing at the surface of blue-and-white tile glazes from a large decorative panel with more than one thousand tiles, called Vista de Lisboa that depicts the city before the destruction caused by the 1755 earthquake. The characterization of green-stained blue-and-white tile glazes was performed using non-destructive X-ray techniques (diffraction and fluorescence spectrometry) by directly irradiating the surface of small tile fragments, complemented by a destructive scanning electron microscopy (SEM) observation of one fragment. Despite the green staining, analytical X-ray data showed that no deterioration had occurred irrespective of the blue or white color, while complementary SEM-EDX data provided chemical evidence of microorganism colonization at the stained glaze surface.

Keywords: Tile panel, Seventeenth-eighteenth centuries, Blue-and-white glazes, Green stains, SEM-EDX, XRD, XRF-WDS

\section{Introduction}

Glazed ceramic tiles ('azulejos' in Portuguese, from the original Arab designation 'al-zulayj') have a wide application in the architectural cultural heritage of the Mediterranean area and their deterioration deserves particular attention. Churches, public buildings, or even palaces were decorated with attractive tiles, placed inside and/or outside the edifice, most of them built hundreds of years ago. Ancient tile panels exposed to different environmental conditions are liable to develop microorganisms that can play a major role in tile pathologies and materials

Correspondence to: Teresa P. Silva, LNEG, Unity of Mineral Resources and Geophysics, Estrada da Portela, Apt. 7586, 2610-999 Amadora, Portugal. Email: teresa.pena@Ineg.pt degradation (e.g. Oliveira et al., 2001; Giacomucci et al., 2011).

A large panel of blue-and-white tiles, named Vista de Lisboa, located at the National Tile Museum (MNAz) (Mântua \& Monteiro, 2010) is the focus of this study. It depicts a panoramic view of the city prior to its destruction due to the earthquake of 1755. The object has undergone successive conservation treatments (the latest in the 1990s), yet small green stains and pinkish discoloration in larger areas are perceptible in the glaze of many tiles (CastelBranco Pereira et al., 1992).

Following a previous study on environmental impacts where green stains observed in decorative blue-and-white tile panels from the sixteenth century 